\title{
Regulation of host immune responses by modification of Salmonella virulence genes
}

\author{
John L. VanCott ${ }^{1}$, Stephen N. Chatfield ${ }^{2}$, Mark Roberts ${ }^{3}$, David M. Hone ${ }^{4}$, \\ Elizabeth L. Hohmann ${ }^{5}$, David W. Pascual ${ }^{6}$, Masafumi Yamamoto ${ }^{7}$, \\ HIROSHI KIYONO ${ }^{7} \&$ JERRY R. MCGHEE ${ }^{8}$ \\ ${ }^{1}$ Children's Hospital Medical Center, Division of Infectious Disease, Cincinnati, Ohio 45229, USA \\ ${ }^{2} \mathrm{~V}$ accine Research Unit, MEDEVA, Department of Biochemistry, Imperial College of Science, \\ Technology and M edicine, London SW 7 2AY, United Kingdom \\ ${ }^{3}$ Department of Veterinary Pathology, University of Glasgow, Bearsden Rd, Glasgow, G61 1QH \\ ${ }^{4}$ Division of Vaccine Research, Institute of Human Virology, Baltimore, Maryland 21201, USA \\ ${ }^{5}$ Infectious Disease Division, Massachusetts General Hospital, Boston, Massachusetts 02114, USA \\ ${ }^{6}$ V eterinary M olecular Biology, M ontana State University, Bozeman, Montana 59717-3610, USA \\ ${ }^{7}$ D epartment of Mucosal Immunology, Research Institute for Microbial Diseases, \\ Osaka University, Osaka 565 JAPAN \\ ${ }^{8}$ D epartment of Microbiology, The Immunobiology Vaccine Center, \\ The University of Alabama at Birmingham, Birmingham, Alabama 35294, USA \\ Correspondence should be addressed to J.L.V.
}

\begin{abstract}
Modifying bacterial virulence genes to probe the nature of host immunity is mostly unexplored. Here we investigate whether host immune responses can be regulated by modification of bacterial virulence genes. In mice, attenuated Salmonella mutant strains with clinical relevance elicited differential host immune responses. Oral administration of a mutant strain with a PhoP-null phenotype promoted potent innate immune responses of macrophages that were sufficient for host defense. In contrast, administration of an Aro- mutant strain elicited stronger specific antibody and T-helper (Th)-cell responses, wherein Th1-type cells were required for clearance. Thus, genetic manipulation of bacteria may be used to broadly alter immune mechanisms that regulate attenuation within the host and to tailor host immunity to specific bacterial pathogens.
\end{abstract}

Modifying virulence genes in bacteria by genetic techniques has facilitated the devel opment of mutant strains that have potential as vaccines and antigen carrier vehicles. In particular, mutant strains of Salmonella have shown promise as live oral vaccines in humans, capable of stimulating both mucosal and systemic immune responses ${ }^{1}$. However, the immune mechanisms involved in host pathology and the roles that bacterial virulence genes have in evading, suppressing and stimulating immune responses have not been fully elucidated ${ }^{2}$.

Survival of Salmonella within the mammalian host is accomplished partly by coordinate expression of virulence genes ${ }^{3}$. In turn, host resistance to Salmonella depends on the action of Th1-type cells and interferon gamma ${ }^{4-6}($ IFN- $\gamma$ ). A variety of defined deletions in Salmonella virulence genes can substantially reduce survival in the host. For example, there has been considerable interest in strains with mutations in phoP-phoQ and aro genes. The PhoP-PhoQ virulence regulon is a bacterial twocomponent regulatory system that controls expression of genes necessary for survival within macrophages and resistance to antimicrobial peptides ${ }^{3}$. Disruption of these genes results in the PhoP-null phenotype ( $\left.^{3} \mathrm{P}^{-}\right)$. In contrast, aro genes regulate synthesis of aromatic acid metabolites that are normally unavailable in mammalian hosts ${ }^{7}$. S. typhimurium $\mathrm{PhoP}^{-}$and $\mathrm{Aro}^{-}$ mutant strains are immunogenic and attenuated for virulence in animal models, as are $\mathrm{PhoP}^{-}$and Aro $^{-}$derivatives of $\mathrm{S}$. typhi in humans $s^{8-12}$.
Here we investigate the effects of the modification of Salmonella virulence genes on immune responses that ensue after the oral inoculation of mice. We focused on Salmonella Aro $^{-}$and $\mathrm{PhoP}^{-}$mutant strains in part because of their relevance to vaccine development. We used immunodeficient animals, mice deficient in IFN- $\gamma\left(\right.$ IFN- $\left.\gamma^{-1}\right)$ (ref. 13) and TCR- $\beta \times \delta^{-1-}$ mice ${ }^{14,15}$, to clarify the relative importance of particular immune pathways involved in the immunogenicity and control of each strain. We show that S. typhimurium Aro and PhoP- mutant $^{-}$ strains promote different immune responses in the host and are not equally susceptible to a variety of host defenses. These results demonstrate that virulence genes in Salmonella can be genetically modified to regulate immune responses.

IFN- $\gamma$ and T cells influence the virulence of Salmonella mutants An Aro mutant of S. typhimurium was highly virulent in IFN$\gamma^{-1-}$ mice after oral inoculation with $5 \times 10^{9}$ colony-forming units (CFU), whereas normal mice tolerated this dose (Fig. 1a and d). Other avirulent mutant strains that were lethal in IFN$\gamma^{-1-}$ mice included a PhoP-constitutive $\left(\mathrm{PhoP}^{\mathrm{c}}\right)$ mutant, with a single amino-acid substitution in the phoQ gene ${ }^{16}$, and mutants blocked in adenylate cyclase synthesis and the cyclic AMP receptor protein ${ }^{17}$ (cya $^{-} \mathrm{crp}^{-}$)and heat-shock proteins ${ }^{10}$ (htr $\mathrm{A}^{-}$)(data not shown). These results indicate a more general requirement for IFN- $\gamma$ in host resistance to a wide array of attenuated S. typhimurium strains $s^{4,5}$. 
Fig. 1 Susceptibilities of normal and IFN $-\gamma^{-1-}$ mice to infection with Aro-and PhoP- S. typhimurium. IFN- $\gamma^{++}(\square)$ and IFN- $\gamma^{-1-}(\square)$ C57BL/ 6 mice were orally inoculated ( $5 \times 10^{9} \mathrm{CFU}$ per mouse) with the Aro $^{-}$strain (a and $\mathbf{d}$ ) and the PhoP' strain (b and e). Other IFN- $\gamma^{H+}$ and IFN- $\gamma^{--}$mice received $1.2 \times$ $10^{10} \mathrm{CFU}$ of the PhoP- strain (c and $\mathbf{f}$ ). The liver, Peyer's patches and spleen showed similar growth kinetics except that the PhoP' strain was occasionally not recovered from spleens and livers of IFN$\gamma^{++}$mice at the detection level of $50 \mathrm{CFU}$; only results from the spleen are shown. Data are from twenty mice per group for survival curves ( $a, b$ and c) and each point in the growth curves (d, e and f) represents the mean $\pm \mathrm{s}$.d. of five mice. The Aro strain was consistently less virulent than wild-type bacteria; a dose of $5 \times 10^{9} \mathrm{CFU}$ of wild-type strain was lethal in less than 7 days in IFN $-\gamma^{H+}$ mice and less than 2 days in IFN- $\gamma^{\prime-}$ mice. $*, \mathrm{P}<0.01 \mathrm{com}$ pared with IFN $-\gamma^{++}$or IFN $-\gamma^{-1-}$ mice.
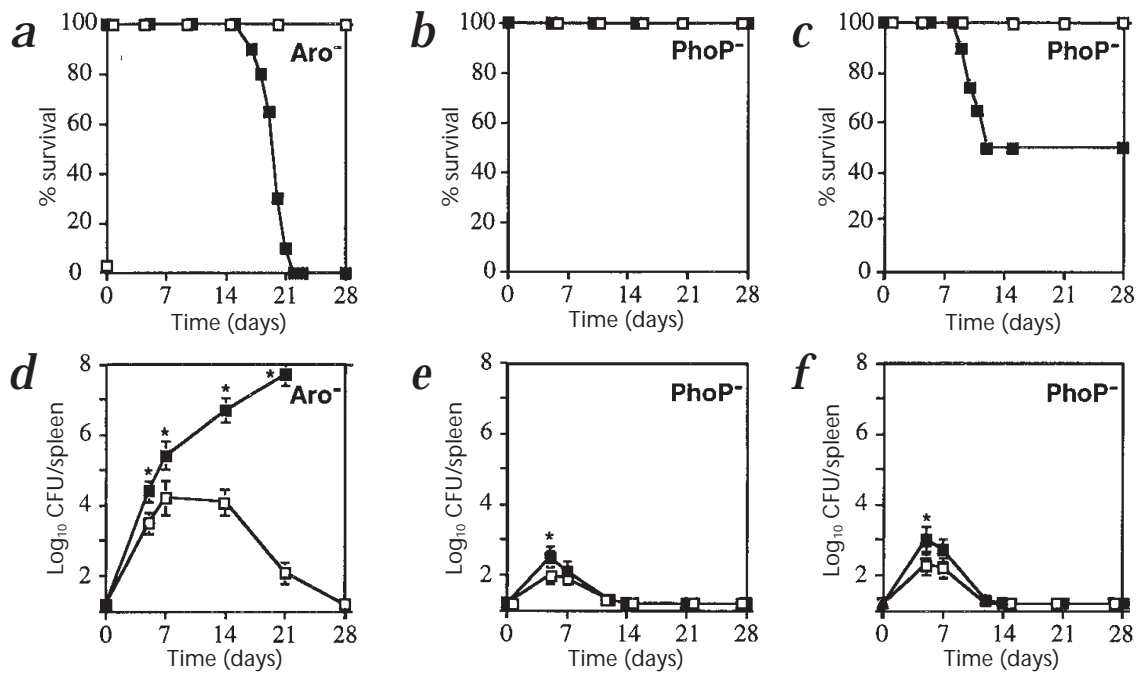

In contrast, a PhoP- mutant strain showed significant attenuation in IFN- $\gamma^{-1-}$ mice (Fig. $1 \mathrm{~b}$ and e). In the absence of IFN- $\gamma$, bacterial burdens were increased by fivefold on day 5 , but clearance was achieved by day 14 (Fig. 1e). Thus, IFN- $\gamma$ influenced the in vivo growth kinetics of both the Aro- and $\mathrm{PhoP}^{-}$ strains of Salmonella, but was only required for clearance of the Aro strain (Fig. 1d and e). When inoculating with a $50 \%$ lethal oral dose $\left(\right.$ LOD $\left._{50} ; 1.2 \times 10^{10} \mathrm{CFU}\right)$ of the PhoP $^{-}$strain, bacterial clearance was achieved before IFN- $\gamma^{-1-}$ mice died (Fig. $1 \mathrm{c}$ and f). Additionally, in TCR- $\beta \times \delta^{-/-}$mice, which lack functional $\alpha \beta$ and $\gamma \delta \mathrm{T}$ cells, only the Aro strain was lethal. The in vivo growth kinetics and timing of the clearance of the PhoP- strain were similar in normal and TCR- $\beta \times \delta^{-1-}$ mice (data not shown), whereas the Aro- strain was lethal in TCR- $\beta \times \delta^{-1-}$ mice after 60 days, a result consistent with previous reports $s^{5,6}$. These results
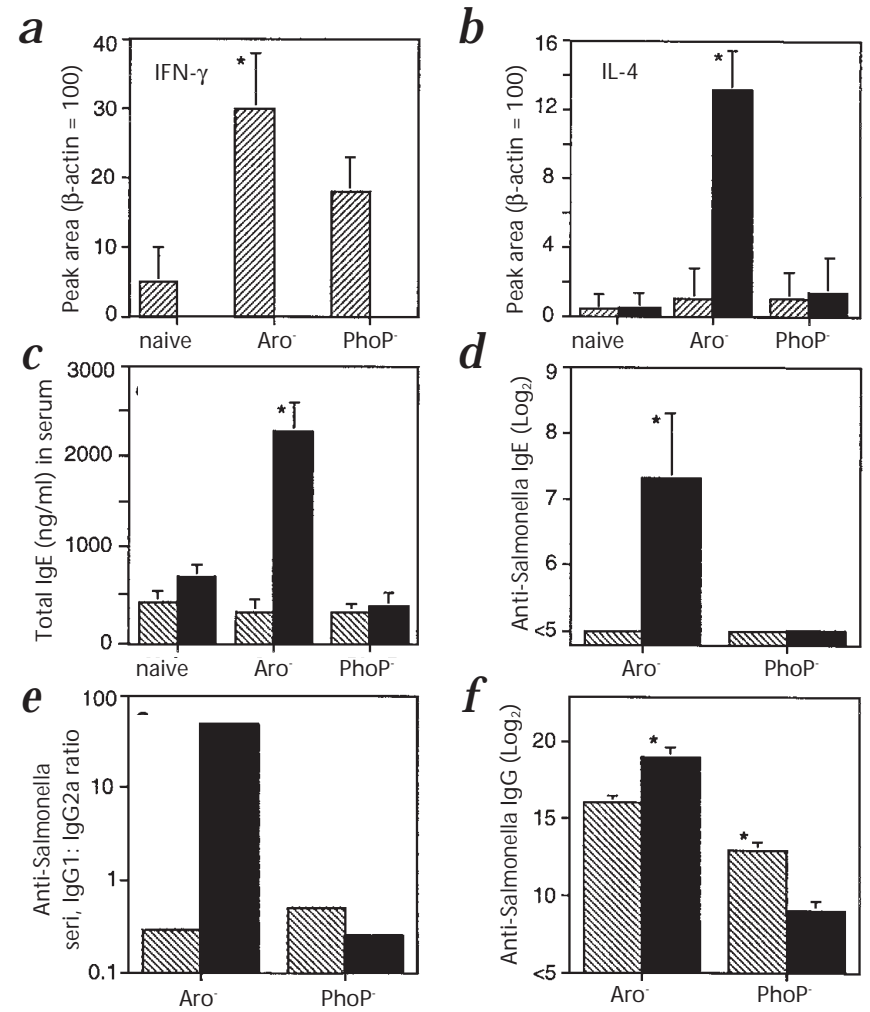

indicated that different immune mechanisms were mediating control of the growth and lethal effects of the two strains within the host.

Effects of Aro- and PhoP- mutant strains on specific immunity

To determine whether the $\mathrm{PhoP}^{-}$and $\mathrm{Aro}^{-}$mutant strains stimulated different host defense mechanisms, we initially characterized the Th phenotype that developed in normal and IFN- $\gamma^{-1-}$ mice. Five days after oral inoculation with $5 \times 10^{9} \mathrm{CFU}$ of each strain, $C D 4^{+} T$ cells were isolated from splenocyte and Peyer's patch populations for analysis of IFN $-\gamma$ and IL-4 mRNA expression. The Aro strain stimulated more Th1-type IFN- $\gamma$ expression than did the PhoP' strain in normal mice (Fig. 2a), and only the Aro- strain stimulated a shift to Th2-type IL-4 expression in IFN$\gamma^{-1-}$ mice (Fig. 2b). Decreasing the dose of the Aro- strain or increasing the dose of the PhoP- strain to produce similar bacterial loads in either normal or IFN- $\gamma^{-1-}$ mice failed to significantly alter the differential abilities of the two strains to induce Th1/Th2 responses (data not shown).

To demonstrate the consequence of Th1- and Th2-cells on serum antibody responses, we measured Salmonella-specific IgE, IgG, and IgG subclass responses. In mice, IFN- $\gamma$ and IL-4 provide essential signals for antibody isotype switching to IgG2a and IgG3 or to IgE and IgG1, respectively ${ }^{18}$. Total IgE levels (Fig. 2c), Salmonella-specific IgE titers (Fig. 2d) and IgG1-to-IgG2a ratios (Fig. 2e) were increased in the sera of IFN- $\gamma^{-1-}$ mice given the Arostrain, whereas no such increases were evident in response to the $\mathrm{PhoP}^{-}$strain. Moreover, the Aro- strain elicited higher Salmonellaspecific IgG titers in normal and IFN- $\gamma^{-1-}$ mice than did the PhoPstrain (Fig. 2f).

Fig. 2 Th1- and Th2-type cytokine profiles and antibody responses in normal and IFN- $\gamma^{1-}$ mice inoculated with Aro-and PhoP- strains of S. typhimurium or uninoculated (naive). IFN- $\gamma$ (a) and IL-4 (b) mRNA expression in $\mathrm{CD}^{+} \mathrm{T}$ cells from the spleens of IFN- $\gamma^{++}(\square)$ and IFN- $\gamma^{--}(\mathbf{\square})$ mice 5 days after oral inoculation with $5 \times 10^{9} \mathrm{CFU}$ of bacteria. Total IgE levels (c), Salmonella-specific IgE titers (d), Salmonella-specific IgG1-to-IgG2a ratios (e) and Salmonella-specific IgG titers (f) in serum samples. Data are expressed as the mean peak area \pm s.d. ( $a$ and $b$ ), $\log _{2}$ endpoint titer $\pm S D(d$ and f) and serum lgE concentration ( $\mathrm{ng} / \mathrm{ml}) \pm \mathrm{s}$.d. (c); and the lgGl:lgG2a ratio of endpoint titers (e) from three experiments with five mice per group. $*, \mathrm{P}<0.01$ compared with IFN- $\gamma^{H+}$ or IFN- $\gamma^{-1-}$ mice. 
Fig. 3 Effect of S. typhimurium mutant strains and wild-type bacteria on antimicrobial production in IFN- $\gamma^{++}$, IFN- $\gamma^{--}$and TCR- $\beta \times \delta^{-1-}$ mice. Mice were orally inoculated with the $\operatorname{Aro}^{-}(\bullet), \mathrm{PhoP}^{-}(\boldsymbol{\square})$ and wild-type $(\triangle)$ strains, and samples were collected and analyzed 5 days later. Inducible NOS mRNA expression in freshly isolated macrophages ( $\mathrm{Mac}-\mathrm{1}^{+}$ $\mathrm{CD}^{-}$) from spleens (a) and Peyer's patches (d). $\mathrm{NO}_{2}{ }^{-}$and $\mathrm{O}_{2}{ }^{-}$release in supernatants from splenic ( $\mathbf{b}$ and $\mathbf{c}$ ) and Peyer's patch (e and f) cultures. A dose of $5 \times 10^{9}$ CFU was used for the $\mathrm{Aro}^{-}$and $\mathrm{PhoP}^{-}$ strains, whereas a lower dose of wild-type bacteria ( $10^{6} \mathrm{CFU}$ ) was used to produce similar bacterial loads in organs of mice infected with the Aro strain and wild-type strain at day 5 . The data represent five experiments with five mice per group (mean \pm s.d.). $*, P<0.01$ compared with IFN- $\gamma^{++}$ and IFN- $\gamma^{-1-}$ mouse groups.

Effects of the Aro- and PhoP- mutant strains on innate immunity $M$ acrophages contribute to the strong innate immune response during salmonellosis by producing antimicrobial agents such as reactive nitrogen and oxygen intermediates ${ }^{19-21}$. Therefore, we investigated whether the two mutant strains had different effects on innate immune responses of macrophages. Measurement of nitric oxide $\left(\mathrm{NO}_{2}^{-}\right)$and $\mathrm{O}_{2}^{-}$release and the inducible form of nitric oxide (NO) synthase (iNOS) mRNA, which catalyzes the release of $\mathrm{NO}_{2}^{-}$, in macrophages from spleens and Peyer's patches showed that the PhoP- strain was a more effective inducer of each in comparison with the Aro and wild-type Salmonella strains (Fig 3). The PhoP- strain had particularly profound effects on macrophages from Peyer's patches and stimulated high level sof i NOS/ $\mathrm{NO}_{2}{ }^{-}$and $\mathrm{O}_{2}{ }^{-}$in the absence of either T cells or IFN- $\gamma$. In contrast, production of antimicrobial factors in splenic macrophages from normal and TCR- $\beta \mathrm{x}$ $\delta^{-1-}$ mice in response to the PhoP- strain was low, possibly because the PhoP- $^{-}$mutant organisms were marginally detectable in the spleens of these mice. Relatively low expression of iNOS occurred after inoculation of the Aro- and wild-type strains at both low and high doses, indicating that the high bacterial loads failed to impede this response (data not shown). Normalization of the data to bacterial burdens showed that the PhoP- $^{-}$strain was more than 300 -fold more efficient in stimulating antimicrobial agents in spleens and Peyer's patches than was the Aro- strain. For example, the Aro- strain elicited 0.017 $\mu \mathrm{M} \mathrm{NO}_{2}^{-} / \mathrm{ml}$ and the PhoP- strain elicited $5 \mu \mathrm{M} \mathrm{NO}_{2}^{-} / \mathrm{ml}$ of culture supernatant per $100 \mathrm{CFU}$ in Peyer's patches from normal mice. Although the Aro strain was a poor inducer of $\mathrm{iNOS} / \mathrm{O}_{2}{ }^{-}$, it elicited higher levels relative to bacterial loads in IFN- $\gamma^{H+}$ (normal) mice and TCR- $\beta \times \delta^{-/-}$mice, in comparison with IFN$\gamma^{1-}$ mice, indicating that IFN $-\gamma$ has an important role in triggering optimal iNOS/O${ }_{2}^{-}$production early after inoculation with the Aro- strain.

Innate immunity to PhoP- LPS is CD14-dependent

Stimulation of macrophages through a CD14-dependent pathway initiates events leading to the release of antimicrobial agents and pro-inflammatory cytokines ${ }^{22}$. The CD14-dependent pathway may be an essential mechanism through which the PhoP- strain activated macrophages even in the absence of IFN- $\gamma$ or $T$ cells. To investigate this, we added live S. typhimurium strains to cultures of splen ocytes from naive IFN $-\gamma^{H+}$, IFN $-\gamma^{-1-}$ and TCR- $\beta \times \delta^{-1-}$ mice in the presence or absence of antiCD14 receptor antibody $(5 \mu \mathrm{g} / \mathrm{ml})$. Without anti-CD14 blockade, the $\mathrm{Aro}^{-}$and wild-type strains were weak inducers of $\mathrm{NO}_{2}^{-}$ (4-6 $\mu \mathrm{M} \mathrm{NO}_{2}{ }^{-} / \mathrm{ml}$ per $5 \times 10^{6}$ splenocytes) in each mouse strain, whereas the $\mathrm{PhoP}^{-}$strain was a potent inducer in all cases (25-35 $\mu \mathrm{M} \mathrm{NO}_{2}^{-} / \mathrm{ml}$ per $5 \times 10^{6}$ splenocytes). $\mathrm{NO}_{2}^{-}$release by splenocytes after stimulation with $\mathrm{PhoP}^{-}$bacteria was abrogated by blockade of the CD14 receptor.

The central role of the CD14 receptor in $\mathrm{NO}_{2}^{-}$release indicated that PhoP- LPS, which contains an altered lipid A structure when compared with wild-type bacteria ${ }^{23}$, may partially account for the increased $\mathrm{NO}_{2}^{-}$response to the PhoP- strain. LPS was purified from wild-type bacteria and $\mathrm{Aro}^{-}$and $\mathrm{PhoP}^{-}$ mutant strains and added ( $10 \mathrm{ng} / \mathrm{ml})$ to IFN- $\gamma^{++}$splenocyte cultures $\left(5 \times 10^{6} \mathrm{cell} / \mathrm{s} / \mathrm{ml}\right)$. After 24 hours, supernatants from splenocytes from PhoP- LPS-stimulated cultures had $42-65 \mu \mathrm{M}$ $\mathrm{NO}_{2}^{-} / \mathrm{ml}$, whereas supernatants from Aro- LPS- and wild-type LPS-stimulated cultures had 5-10 $\mu \mathrm{M} \mathrm{NO}_{2}^{-} / \mathrm{ml}$.

\section{Different immune mechanisms control Salmonella mutants}

The above results showed that early control and subsequent clearance of the Aro- strain required IFN- $\gamma$ and Th 1 cells. To investigate the in vivo mechanism responsible for control of the $\mathrm{PhoP}^{-}$strain, we treated IFN- $\gamma^{++}$and IFN- $\gamma^{-1-}$ mice with in-

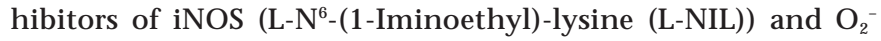
(allopurinol) and with antibody against TNF- $\alpha$. Inhibition of either iNOS or TNF- $\alpha$ had little effect on the in vivo growth of the PhoP- mutant strain, whereas its virulence was significantly enhanced by inhibition of $\mathrm{O}_{2}^{-}$(Fig. 4a and b). Conversely, inhibition of iNOS and $\mathrm{O}_{2}^{-}$had little effect on Aro- virulence, whereas recombinant TNF- $\alpha$ reduced and anti-TNF- $\alpha$ antibody increased Aro- virulence (Fig. $4 a$ and b). Mouse strains with the Ity' genotype have increased iNOS activity and increased resis- 


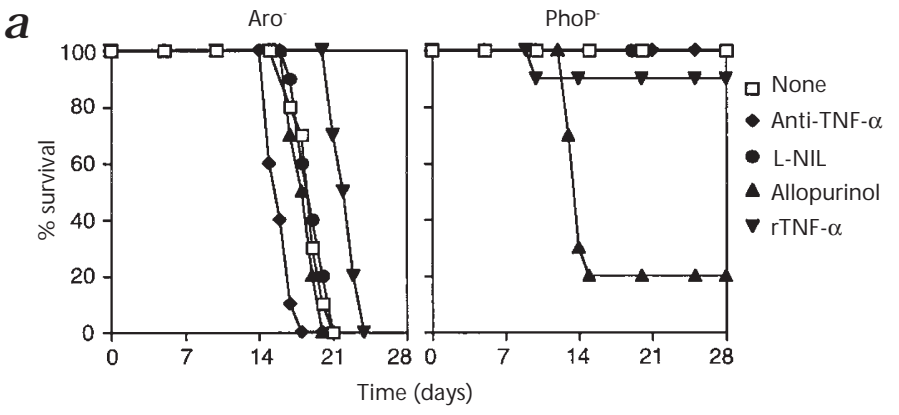

Fig. 4 Effects of L-NIL, allopurinol, TNF- $\alpha$ neutralization and recombinant TNF- $\alpha$ on the virulence of Aro and PhoP- $^{-}$S. typhimurium in mice. Survival rate of IFN $\gamma^{-1-}$ mice (a) and growth of the Aro-and PhoP'strains in Peyer's patches of IFN- $\gamma^{++}(\square)$ and IFN- $\gamma^{-1-}(\square)$ mice (b) after oral inoculation with $5 \times 10^{9} \mathrm{CFU}$. The survival rate of IFN- $\gamma^{+++}$mice was $100 \%$ for all b

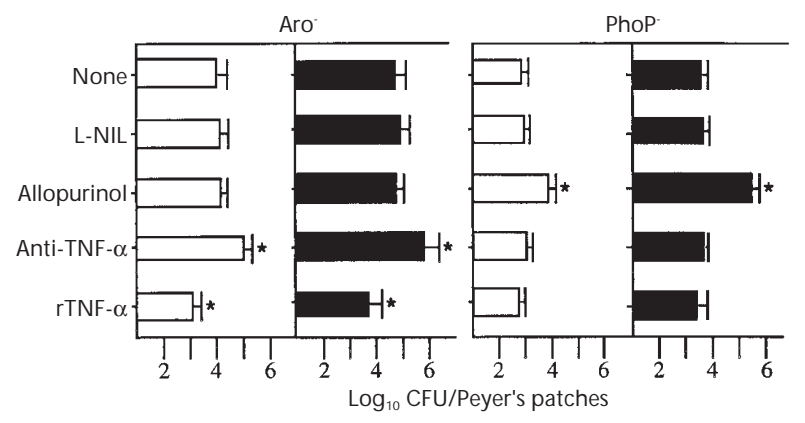

conditions (data not shown in a). No mortality occurred in control mice receiving L-NIL, allopurinol, anti-TNF- $\alpha$ antibody or rTNF- $\alpha$ alone. The data represent the mean \pm s.d. of five (a) and ten (b) mice per group. *, P $<0.01$ compared with control group of mice (None), infected but without treatment. tance to Salmonella infection ${ }^{24,25}$, supporting the hypothesis that the relative impact of $\mathrm{NO}$ and possibly other antimicrobial factors on Salmonella virulence may differ substantially among mouse strains. To investigate this, we inoculated groups of 10 $\mathrm{C} 3 \mathrm{H} / \mathrm{HeN}$ mice $\left(\mathrm{Ity}^{\mathrm{r}}\right)$ with $5 \times 10^{9} \mathrm{CFU}$ of the Aro strain or the PhoP- strain and provided L-NIL $(4.5 \mathrm{mM})$ in their drinking water. All of the mice survived the infection. However, on day 14 , bacterial loads in the organs of mice treated with L-NIL and infected with the Aro strain were elevated 10-fold compared with those in the untreated control $\mathrm{C} 3 \mathrm{H} / \mathrm{HeN}$ mice $(\mathrm{P}<0.01)$. Bacterial loads in $\mathrm{C} 3 \mathrm{H} / \mathrm{HeN}$ mice infected with the $\mathrm{PhoP}^{-}$strain and given L-NIL, however, were increased by less than twofold compared with untreated controls. Thus, inhibition of iNOS production in $\mathrm{C} 3 \mathrm{H} / \mathrm{HeN}$ mice by L-NIL treatment increased the virulence of the Aro ${ }^{-}$strain, but had little effect on the growth of the PhoP $^{-}$strain.

\section{The toxic and immunosuppressive effects of the PhoP- strain} We next studied whether NO or inflammatory cytokines (endogenous effector molecules of LPS-induced endotoxic shock ${ }^{26,27}$ ) could account for the lethal effects of the PhoP- strain in IFN- $\gamma^{-1-}$ mice (Fig. 1C). The PhoP- strain stimulated more TNF$\alpha, I L-1 \beta$ and serum amyloid P (SAP) in sera from IFN- $\gamma^{-1-}$ mice than did the Aro strain (Fig. 5). Therefore, to determine whether these molecules had detrimental effects in PhoP-infected mice, we treated IFN $-\gamma^{-1-}$ mice with neutralizing antibody to either IL-1 $\beta$ or TNF- $\alpha$ and inoculated them with the LOD $D_{50}$ of the PhoP- strain. By day 14 after inoculation [AUTHOR: OK?], 4 of 10 mice in the untreated group had died, whereas 0 of 10 and 1 of 10 mice treated with anti-IL-1 $\beta$ antibody and anti-TNF- $\alpha$ antibody, respectively, died; treatment with L-NIL failed to protect IFN- $\gamma^{-1-}$ mice from the lethal effects of the PhoP- strain.

NO has been shown to impart immunosuppressive effects during murine salmonellosis ${ }^{28,29}$. To determine whether there was an inverse relationship between NO and specific immune responses, we measured Salmonella-specific IgG responses in normal and IFN $-\gamma^{1-}$ mice treated with L-NIL. By day 12 , serum IgG titers were increased by sixfold $(\mathrm{P}<0.01)$ in PhoP-infected IFN- $\gamma^{-1-}$ mice, and by threefold in PhoP-infected normal mice treated with L-NIL, whereas IgG titers were not increased further in mice inoculated with the Aro- strain (data not shown). These results indicated that NO was partially responsible for the reduced Salmonella-specific immune responses early after inoculation with the PhoP' strain.

\section{Discussion}

We report here that $\mathrm{Aro}^{-}$and $\mathrm{PhoP}^{-}$mutant strains of Salmonella invoked different immune responses in mice. We also found that IFN- $\gamma$ and $T$ cells were essential for distinguishing the immune mechanisms elicited to the two mutant strains in vivo. The PhoP- strain stimulated the innate immune responses of macrophages with greater efficiency than did the Aro $^{-}$strain, whereas the Aro- strain promoted the development of higher immune responses of $B$ cells and Th cells. In the absence of IFN- $\gamma$, infection with the PhoP- $^{-}$strain led to higher bacterial loads in systemic tissues and increased levels of toxic molecules in the circulation, such as $\mathrm{NO}_{2}^{-}, \mathrm{IL}-1 \beta$ and SAP. However, in the presence of IFN- $\gamma$, the PhoP- $^{-}$strain was less able to reach systemic tissues in normal mice. Consequently, in the presence of IFN- $\gamma$, the PhoP $^{-}$strain had more profound effects on local macrophage activity, resulting in limited proinflammatory and immunosuppressive effects in the systemic compartment.

During infection with the Aro- strain, IFN $-\gamma$ was necessary to trigger antimicrobial activity of macrophages, essential for early bacterial control. In the absence of IFN- $\gamma$, the Aro- strain stimulated strong Th2-type and IgG1/IgE responses but macrophage activity was negl igible; the Aro strain al so showed uncontrolled growth, demonstrating that Th2-type responses were inadequate to effect immunity to this strain. Although in vivo growth

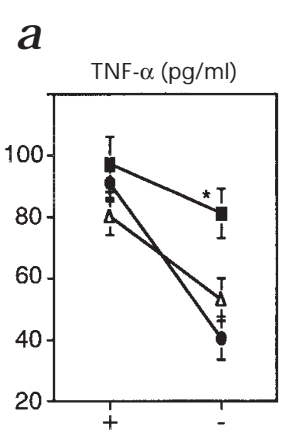

b

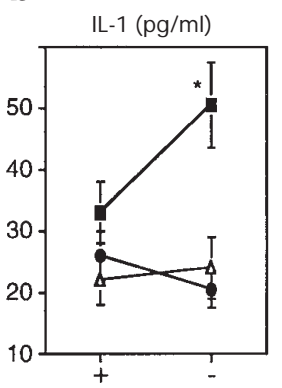

C

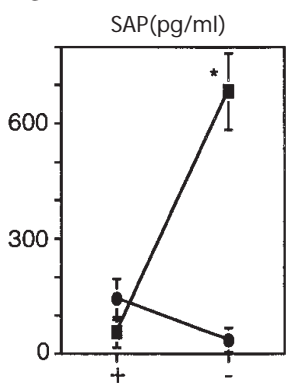

Fig. 5 Effect of S. typhimurium mutant strains and wild-type bacteria on inflammatory responses in normal and IFN- $\gamma^{-1-}$ mice. Mice were orally inoculated with the $\operatorname{Aro}^{-}(\bullet), \operatorname{PhoP}^{-}(\boldsymbol{\square})$ and wild-type $(\triangle)$ strains, and samples were collected and analyzed 5 days later. Serum levels of TNF- $\alpha$ (a) IL-1 $\beta$ (b) and SAP (c). The data represent five experiments with five mice per group (mean \pm s.d.). $*, P<0.01$ compared with the other Salmonella-infected IFN- $\gamma^{1-}$ mouse groups. 
of the Aro- strain was controlled by mechanisms dependent on IFN- $\gamma$ in the absence of T cells for up to 60 days, Th 1 cells were subsequently needed for clearance. In contrast, the PhoP' strain stimulated potent antimicrobial macrophage activity whether or not T cells or IFN- $\gamma$ were available. Moreover, in the absence of T cells or IFN- $\gamma$ and combined with the extreme sensitivity of the PhoP- mutant strain to the respi ratory burst $\left(\mathrm{O}_{2}^{-}\right)$, innate immune mechan isms were sufficient for its control. Other host responses, such as defensins ${ }^{30-32}$ or the host environmental milieu (for example, low magnesium concentration ${ }^{33}$ ), may have also contributed to the control of the PhoP- strain. Thus, defined mutations in virulence genes can have profound effects on Salmonella immunogenicity within the host and the resulting effector responses.

To determine whether the differences in the immune re sponses to the $\mathrm{PhoP}^{-}$and Aro- strains were attributable to differences in overall bacterial loads, we analyzed the ability of Iower doses of the Aro- strain or higher doses of the PhoP- strain to elicit specific and innate immune responses. These experiments confirmed a greater ability of the PhoP- strain to elicit $\mathrm{NO}_{2}^{-}$and $\mathrm{O}_{2}^{-}$in both normal and IFN- $\gamma^{-1-}$ mice and the Aro- strain to stimulate Th and antibody responses. Moreover, analysis of similar amounts of LPS from PhoP- ${ }^{-}$Aro ${ }^{-}$and wildtype bacteria showed that the PhoP- ${ }^{-}$PS induced more $\mathrm{NO}_{2}{ }^{-}$in vitro. These results were consistent with a previous report showing that PhoP- LPS stimulated more endothelial E-selectin expression and more monocyte TNF- $\alpha$ expression in vitro than wild-type LPS ${ }^{23}$. Similarly, LPS from spontaneous variants of Francisella tularenis induced different amounts of $\mathrm{NO}_{2}^{-}$in rat macrophages ${ }^{34}$. Our observations show that mutant strains of bacteria may be generated that induce qualitatively distinct immune responsesin vivo.

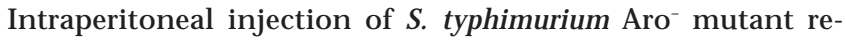
sulted in more NO production and immunosuppression in spleens from $\mathrm{C} 3 \mathrm{HeB} / \mathrm{Fe}$ mice (Ity ${ }^{r}$ ) than did the same dose of a PhoP- $^{-}$mutant ${ }^{35}$. Therefore, the higher NO production in response to the Aro- strain may have reflected the overwhelmingly higher number of Aro organisms (as many as $10^{6} \mathrm{CFU}$ ) in comparison with the number of PhoP- organisms (fewer than 250 CFU) in spleens of these mice ${ }^{35}$. Thus, when NO production was normalized to bacterial loads in the present study, we showed that the $\mathrm{PhoP}^{-}$strain was 300 -fold more efficient than the Aro- strain in stimulating splenic $\mathrm{NO}_{2}^{-}$release. Moreover, the PhoP- strain stimulated more total $\mathrm{NO}_{2}^{-}$in local Peyer's patches than did the Aro-strain.

Our observations demonstrate a delicate balance between Salmonella virulence/attenuation and inflammation within the host. Defined alterations of phoP-phoQ virulence genes and in genes involved in aromatic biosynthesis resulted in distinct effects on attenuation and on both specific and innate immune responses in the host. IFN- $\gamma$ was not required for clearance of the PhoP- strain, whereas alteration in the PhoP-PhoQ regulon, yielding the $\mathrm{PhoP}^{\mathrm{c}}$ strain, resulted in IFN- $\gamma$-dependent clearance. The ability of the PhoP- strain to elicit high levels of reactive nitrogen and oxygen intermediates is relevant to possible anti-neoplastic therapeutic application of salmonellae ${ }^{36}$. Thus, by manipulating virulence genes, bacterial mutants could be produced that specifically modulate immune mechanisms within the host (that is, pathways independent of $\mathrm{T}$ cells involving $\mathrm{CD} 14$ and $\mathrm{iNOS} / \mathrm{O}_{2}{ }^{-}$, or Th1-dependent pathways). It remains important to continue to identify virulent genes in this manner to enable selection of new attenuation strategies for defined medical purposes.

\section{Methods}

Mice. IFN- $\gamma^{\prime-}$ and IFN- $\gamma^{++}$mice of a C57BL/ 6 background and $\mathrm{C} 3 \mathrm{H} / \mathrm{HeN}$ mice were obtained from the Jackson Laboratories (Bar Harbor, Maine). TCR- $\beta \times \gamma^{-1-}$ mice of a C57BL/ 6 background were supplied by S. Tonegawa and $\mathrm{K}$. Fujihashi ${ }^{14,15}$. All mice were provided sterile food and water ad libitum and maintained in pathogen-free conditions in animal facilities of the UAB Immunobiology Vaccine Center. Animal care was in accordance with institutional guidelines.

Reagents and in vivo treatments. Anti-CD14 receptor antibody (rmC5-3; Zymed, San Diego, California) was added to splenic and Peyer's patch cultures $\left(5 \times 10^{6} \mathrm{cells} / \mathrm{ml}\right)$ at $5 \mu \mathrm{g} / \mathrm{ml} . \mathrm{NO}_{2}{ }^{-}$and $\mathrm{O}_{2}{ }^{-}$in 24 -hour culture supernatants were assayed by the Griess method to measure nitrite generated from $\mathrm{NO}_{2}^{-}$(ref. 37) and by reduction of ferricytochrome $\mathrm{C}$ to measure superoxide production ${ }^{38}$. L-NIL (Alexis, San Diego, California) was added to the drinking water $(4.5 \mathrm{mM})$ over a 4-week period. Allopurinol (400 $\mu \mathrm{g} /$ mouse per day; Sigma) in $200 \mu \mathrm{l}$ of $0.25 \mathrm{mM} \mathrm{NaOH}$ was administered by oral intubation on days 1-5 and 8-12; higher or additional doses were toxic (based on the appearance of ruffled fur, weight loss and lethargy in mice). An intraperitoneal dose of $2 \times 10^{4} \mathrm{U} /$ mouse of rabbit anti-mouse TNF- $\alpha$ (IP-400; Genzyme, Cambridge, Massachusetts) in $200 \mu$ l of PBS was administered at the time of Salmonella administration and repeated 2 and 14 days later. Treatment with recombinant TNF- $\alpha$ (TNF-M; Genzyme, Cambridge, Massachusetts) was achieved by intraperitoneal injection with $1 \mu \mathrm{g}$ in $100 \mu \mathrm{l}$ of PBS at the time of inoculation and again 14 days later. Treatment with IL-1 $\beta$ was accomplished by intraperitoneal injection with $600 \mu \mathrm{g} /$ mouse on day 0 and again on day 14 (1997-01, Genzyme, Cambridge, Massachusetts). LPS was purified from the Aro and PhoPstrains and wild-type bacteria as described ${ }^{39}$. The number of bacteria present in spleens of mice were determined by viable count of organ homogenates on LB agar ${ }^{10}$.

Salmonella strains. The three attenuated S. typhimurium strains used in this work were derived from wild-type strain ATCC14028. The PhoP- strain (LH430) has a 956-bp deletion in the contiguous phoP-phoQ genes; this inframe deletion is identical to that in S. typhi Ty800 (ref. 12). The AroA- strain (SL7731) has aroA $\Delta 407$ mobilized through P22HT from SL7728 using linkage of the transposon insertion serC $1121:: \operatorname{Tn} 10$ by transduction; this aro $\mathrm{A}^{-}$ deletion allele is identical to that in S. typhimurium SL3261, the strain most extensively evaluted in mice ${ }^{7}$. The PhoP ${ }^{\mathrm{c}}$ strain (CS022) has pho-24 mobilized through P22HT from strain TA2367 (ref. 16). Other attenuated S. typhimurium strains studied included an htrA- mutant (BRD726) derived from wild-type strain SL1344 (ref. 10) and a cya- crp- mutant ( $\chi 4062$ ) derived from wild-type strain SR-11 (ref. 17).

Antibody analysis. Total IgE levels in sera were determined by ELISA. For this assay, Falcon MicroTest III plates (Becton Dickinson, San Jose, California) were coated with $2 \mu \mathrm{g} / \mathrm{ml}$ of rat monoclonal anti-mouse IgE antibody (R35-72; PharMingen, San Diego, California). Serial dilutions of standard mouse IgE (PharMingen, San Diego, California) were then added followed by addition of $100 \mu \mathrm{l}$ of a biotinylated rat monoclonal anti-mouse IgE antibody (R35-92; PharMingen, San Diego, California). Peroxidase-labeled streptavidin was used for detection and plates were then developed with the chromogenic substrate, ABTS with $\mathrm{H}_{2} \mathrm{O}_{2}$ (Moss, Pasadena, Maryland). Antigen-specific IgE titers in sera were determined by endpoint ELISA using biotinylated monclonal antibodies specific for IgE (R35-92) and streptavidin-conjugated, polyadenylated peroxidase-80 (1:2000 dilution; Research Diagnostics, Flanders, New Jersey). The coating antigen was heatkilled preparations of S. typhimurium. Salmonella-specific IgG1 and IgG2a antibody titers in sera were determined by endpoint ELISA (ref. 40). Biotinylated monoclonal antibodies specific for IgG1 and IgG2a and streptavidin-conjugated peroxidase were employed (PharMingen, San Diego, California).

Th1/Th2 analysis. CD4 ${ }^{+}$Mac- $1^{-}$T cells and CD4- Mac- $1^{+}$spleen and Peyer's patch cells were purified by flow cytometry using FITC-conjugated antiL3T4 monclonal antibody (GK 1.5) and biotinylated anti-CD11b (Mac-1) antibodies and PE-conjugated streptavidin ${ }^{40}$ (PharMingen, San Diego, California). Total RNA was isolated from $\mathrm{CD} 4{ }^{+} \mathrm{T}$ cells and Mac- $1^{+}$cells with 
Tri-Reagent (Molecular Research Center, Cincinnati, Ohio) and reversetranscribed with Superscript RT (Promega) according to standard protocols. The resulting CDNA was subjected to PCR amplification using IFN- $\gamma$, IL-4 and iNOS-specific primers ${ }^{41,42}$. Levels of amplified CDNA were determined by capillary electrophoresis ${ }^{41}$ (P/ACE 5000 Beckman Instruments, Fullerton, California). All cytokine and iNOS values were normalized to the corresponding $\beta$-actin values ${ }^{41}$.

Pro-inflammatory cytokines. Serum levels of TNF- $\alpha$ and IL-1 $\beta$ were determined by ELISA using Quantikine ${ }^{T M} M$ kits from R\&D systems (Minneapolis, Minnesota). SAP in serum was also assayed by ELISA ${ }^{43}$.

\section{Acknowledgments}

We thank F. Fang for critical reading of the manuscript, B. Stocker for construction of strain SL7731 for these studies, and A. Szalai for running SAP ELISA. This work was supported by NIH grants AI 18958, DK 44240, RR 13149 and USDA grant 9602195 , as well as grants from the M inistry of Education, Science, Sports and Culture and OPSR in Japan.

\section{RECEIVED 13 APRIL; ACCEPTED 10 SEPTEMBER 1998}

1. Levine, M.M. et al. Attenuated Salmonella as live oral vaccines against typhoid fever and as live vectors. J. Biotech. 44, 193-196 (1996).

2. Jones, B.D. \& Falkow, S. in Annual Review of Immunology Vol. 14 (eds. W.E. Paul, W.E., Fathman, C.G., \& Metzger, H.) 533 (Annual Reviews, Palo Alto, California, 1996)

3. Miller, S.I. Kukraal, A.M \& Mekalanos, J. A two-component regulatory sys tem (phoP phoQ) controls Salmonella typhimurium virulence. Proc. Natl. Acad. Sci. USA 86, 5054-5058 (1989)

4. VanCott, J.L. et al. The host response to mucosal vaccines in the context of targeted gene knockout mice. M ucosal Immunol. Update 3 4, 12-14 (1995).

5. Hess, J., Ladel, C., Miko, D. \& Kaufmann, S.H.E. Salmonella typhimurium aroA infection in gene-targeted immunodeficient mice: major role of CD4 $4^{+} \mathrm{TCR}-\alpha \beta$ cells and IFN- $\gamma$ in bacterial clearance independent of intracellular location. J. Immunol. 156, 3321-3326 (1996).

6. Weintraub, B.C. et al. Role of $\alpha \beta$ and $\gamma \delta$ T cells in the host response to Salmonella infection as demonstrated in T-cell-receptor-deficient mice of de fined Ity genotypes. Infect. Immun. 65, 2306-2312 (1997).

7. Hoiseth, S.K. \& Stocker, B.A.D. Aromatic-dependent Salmonella typhimurium are non-virulent and effective as live vaccines. N ature 291, 238-239 (1981).

8. Galan, J.E. \& R. Curtiss, III., R. Virulence and vaccine potential of phoP mutants of Salmonella typhimurium. Microb. Pathog. 6, 433-443 (1989).

9. Chatfield, S.N. et al. Use of the nirB promoter to direct the stable expression of heterologous antigens in Salmonella oral vaccine strains: development of a single-dose oral tetanus vaccine. Bio/Technology 10, 888-892 (1992).

10. Chatfield, S.N. et al. Evaluation of Salmonella typhimurium strains harbouring defined mutations in htrA and aroA in the murine salmonellosis model. Microb. Pathog. 12, 145-151 (1992).

11. Tacket, C.O. et al. Comparison of the safety and immunogenicity of delta aroC delta aroD and delta cya delta crp Salmonella typhi strains in adult volunteers. Infect. Immun. 60, 536-541 (1992).

12. Hohmann, E.L., Oletta, C.A. \& Miller, S.I. Evaluation of a phoP/phoQ-deleted aroA-deleted live oral Salmonella typhi vaccine strain in human volunteers. Vaccine 14, 19-24 (1996).

13. Dalton, D.K. et al. Multiple defects of immune cell function in mice with dis rupted interferon-gamma genes. Science 259, 1739-1742 (1993).

14. Mombaerts, P. et al. Mutations in T-cell antigen receptor genes alpha and beta block thymocyte development at different stages. Nature 360, 225-231 (1992).

15. Itohara, S. et al. T cell receptor delta gene mutant mice: independent generation of alpha beta $T$ cells and programmed rearrangements of gamma delta TCR genes. Cell 72, 337-348 (1993).

16. Miller, S.I. \& Mekalanos, J.J. Constitutive expression of the phoP regulon attenuates Salmonella virulence and survival within macrophages. J. Bacteriol. 172, 2485-2490 (1990).

17. Curtiss, R. \& Kelly, S.M. Salmonella typhimurium deletion mutants lacking adenylate cyclase and cyclic AMP receptor protein are avirulent and immuno- genic. Infect. Immun. 55, 3035-3043 (1987)

18. Snapper, C.F. \& Finkelman, F.D. in Fundamental Immunology 3rd edn. (ed. Paul, W.E.) 837-863 (Raven, New York, 1993).

19. De Groote, M.A., Testerman, T., Xu, Y., Stauffer, G., \& Fang, F.C. Homocysteine antagonism of nitric oxide-related cytostasis in Salmonella typhimurium. Science 272, 414-417 (1996).

20. Umezawa, K.H. et al. Induction of nitric oxide synthesis and xanthine oxidase and their roles in the antimicrobial mechanism against Salmonella typhimurium infection in mice. Infect. Immun. 65, 2932-2940 (1997).

21. Edwards III, C.K. et al. In vivo administration of recombinant growth hormone or gamma interferon activates macrophages: enhanced resistance to experimental Salmonella typhimurium infection is correlated with generation of reactive oxygen intermediates. Infect. Immun. 60, 2514-2521 (1992).

22. Wright, S.D., Ramos, R.A., Tobias, P.S., Ulevitch, R.J., \& Mathison, J.C. CD14, a receptor for complexes of lipopolysaccharide (LPS) and LPS binding protein Science 249, 1431-1433 (1990).

23. Guo, L. et al. Regulation of lipid A modifications by Salmonella typhimurium virulence genes phoP-phoQ. Science 11, 250-253 (1997).

24. Vidal, S. et al. The Ity/Lsh/Bcg locus: natural resistance to infection with intracellular parasites is abrogated by disruption of the Nrampl gene. J. Exp. Med. 182, 655-656 (1995).

25. Lissner, C.R. Swanson, R.N. \& O'Brien, A.D. Genetic control of the innate resistance of mice to Salmonella typhimurium: expression of the Ity gene in peritoneal and splenic macrophages isolated in vitro. J. Immunol. 131, 3006-3013 (1983).

26. Thiemermann, $C$. The role of the L-Arginine: nitric oxide pathway in circulatory shock. Adv. Pharmacol. 28, 45-79 (1994).

27. Gotschlich, E.C. in Fundamental Immunology 3rd edn. (ed. Paul, W.E.) 1287-1308 (Raven, New York, 1993).

28. al-Ramadi, B.K., Brodkin, M.A., Mosser, D.M., \& Eisenstein, T.K. Immunosuppression induced by attenuated Salmonella. J. Immunol. 146, 2737-2746 (1991).

29. al-Ramadi, B.K., Meiss, Jr., J.J., Huang, D., \& Eisenstein, T.K. Immunosuppression induced by nitric oxide and its inhibition by interleukin-4. Eur. J. Immunol. 22, 2249-2254 (1992).

30. Miller, S.I., Pulkkinen, W.S., Selsted, M.E. \& Mekalanos, J.J. Characterization of defensin resistance phenotypes associated with mutations in the phoP virulence regulon of Salmonella typhimurium. Infect. Immun. 58, 3706-3710 (1990).

31. Miller, S.I. PhoP/PhoQ: macrophage-specific modulators of Salmonella virulence? M ol. Microbiol. 5, 2073-2078 (1991).

32. Gunn, J.S. \& Miller, S.I. PhoP-PhoQ activates transcription of pmrAB, encoding a two-component regulatory system involved in Salmonella typhimurium antimicrobial peptide resistance. J. Bacteriol. 178, 6857-6864 (1996).

33. Soncini, F.C., Vescovi, G.E., Solmon, F., \& Groisman, E.A. Molecular basis of the magnesium deprivation response in Salmonella typhimurium: identification of PhoP-regulated genes. J. Bacteriol. 178, 5092-5099 (1996).

34. Cowley, S.C., Myltseva, S.V. \& Nano, F.E. Phase variation in Francisella tularensis affecting intracellular growth, lipopolysaccharide antigenicity and nitric oxide production. Mol. Microbiol. 20, 867-874 (1996).

35. Eisenstein, T.K., Meissler J.J. Jr., Miller, S.I. \& Stocker, B.A.D. Immunosuppression and nitric oxide production induced by parenteral live Salmonella vaccines do not correlate with protective capacity: a phoP::Tn10 mutant does not suppress but does protect. Vaccine 16, 24-32 (1998).

36. Pawelek, J.M., Low, K.B. \& Bermudes, D. Tumor-targeted Salmonella as a novel anticancer vector. Cancer Res. 57, 4537-4544 (1997).

37. Green, L.C. et al. Analysis of nitrate, nitrite, and $\left[{ }^{15} \mathrm{~N}\right]$ nitrate in biological fluids. Anal. Biochem. 126, 131-138 (1982)

38. Gangadharam, P.R. \& Edwards III, C.K. Release of superoxide anion from resident and activated mouse peritoneal macrophages infected with Mycobacterium intracellulare. Am. Rev. Respir. Dis. 130, 834-838 (1984).

39. Darveau, R.P. \& Hancock, R.E. Procedure for isolation of bacterial lipopolysaccharides from both smooth and rough Pseudomonas aeruginosa and Salmonella typhimurium strains. J. Bacteriol. 155, 831-838 (1983).

40. VanCott. J.L. et al. Regulation of mucosal and systemic antibody responses by $T$ helper cell subsets, macrophages, and derived cytokines following oral immunization with live recombinant Salmonella. J. Immunol. 156, 1504-1514 (1996).

41. Fujihashi, K. et al. in Methods of Microbiology: Immunology of Infection (eds. Kaufman, S.H.E. \& Kabelitz, D.) 257-286 (Academic, San Diego, 1998).

42. Yang, J., Kawamura, I., Zhu, H., \& Mitsuyama, M. Involvement of natural killer cells in nitric oxide production by spleen cells after stimulation with Mycobacterium bovis BCG. J. Immunol. 155, 5728-5735 (1995).

43. Szalai, A.J., Briles, D.E. \& Volanakis, J.E. Human C-reactive protein is protective against fatal Streptococcus pneumoniae infection in transgenic mice. J. Immunol. 155, 2557-2563 (1995). 